\title{
Membrane-associated NADH dehydrogenase activities in Rhodobacter capsulatus: purification of a dihydrolipoyl dehydrogenase
}

\author{
Ben C. Berks, Alastair G. McEwan $\dagger$ and Stuart J. Ferguson* \\ Department of Biochemistry, University of Oxford, South Parks Road, Oxford OX1 3QU, UK
}

(Received 1 February 1993; accepted 23 March 1993)

\begin{abstract}
The presence of several NADH dehydrogenase activities associated with cytoplasmic membrane vesicles of chemoheterotrophically grown Rhodobacter capsulatus MT1131 was demonstrated by combining isoelectric focusing with NADH-tetranitrobluetetrazolium activity staining, a procedure that should have general applicability in the analysis of bacterial NADH dehydrogenase activities. Low $\mathrm{pI}(\mathrm{pI}=5.7)$, Mid $\mathrm{pI}(\mathrm{pI}=6.9)$ and High $\mathrm{pI}$ ( $\mathrm{PI}=\mathbf{8 . 5}$ ) bands were resolved. The Mid pI NADH dehydrogenase activity was purified and identified as a dihydrolipoyl dehydrogenase. Our data indicate that this dihydrolipoyl dehydrogenase is derived from a 2-oxoacid dehydrogenase complex which is associated with the cytoplasmic membrane.
\end{abstract}

\section{Introduction}

The electron transport system of the photosynthetic purple non-sulphur bacterium Rhodobacter capsulatus has been extensively studied. The emphasis has been on the components of the light-driven cyclic electron transport system, including the ubiquinol-cytochrome $c_{2}$ oxidoreductase (cytochrome $b c_{1}$ complex), and upon the cytochrome oxidases. Much less attention has been paid to enzyme activities that are involved in the oxidation of $\mathrm{NADH}$. Indeed, relatively little is known in general about enzyme activities in bacterial cytoplasmic membranes that exhibit NADH dehydrogenase activity (Yagi, 1991; Berks \& Ferguson, 1991). On the basis of inhibitor titrations (Klemme, 1969; La Monica \& Marrs, 1976; Berks, 1991), EPR studies (Zannoni \& Ingledew, 1983; also mentioned in Meinhardt et al., 1989) and molecular genetic analysis (Marrs et al., 1972; Dupuis, 1992), $R$. capsulatus is thought to possess a mitochondrial-type proton-translocating NADH-ubiquinone oxidoreductase. This type of enzyme has not been purified in an intact state from any bacterium. FAD-containing

*Author for correspondence. Tel. (0865) 275240; fax (0865) 275259.

$\dagger$ Present address: School of Biological Sciences, University of East Anglia, Norwich NR4 7TJ, UK.

Abbreviations: $\mathrm{APAD}^{+}$, acetyl pyridine adenine dinucleotide; BCA, bicinchoninic acid; $\mathrm{C}_{12} \mathrm{E}_{8}$, octaethylene glycol monododecyl ether; CIE, crossed immunoelectrophoresis; DB, 2,3-dimethoxy-5-methyl1,6-benzoquinone; dNADH, deamino-NADH (reduced nicotinamide hypoxanthine dinucleotide); DTT, dithiothreitol; IEF, isoelectric focusing; PMSF, phenylmethylsulphonylfluoride; TNBT, tetranitrobluetetrazolium.
$\mathrm{NADH}$-quinone oxidoreductases that do not translocate protons are apparently widespread in bacteria (Yagi, 1991) and it has been suggested that an enzyme of this type is present in $R$. capsulatus (Meinhardt et al., 1990). A third type of cytoplasmic membrane NADH dehydrogenase has been purified from $R$. capsulatus by Ohshima \& Drews (1981). This enzyme, apparently containing six identical subunits of molecular mass $15 \mathrm{kDa}$, is not obviously related to any previously described NADH dehydrogenase. A proton-translocating NADH/NADPH transhydrogenase activity is also present in $R$. capsulatus cytoplasmic membranes (Lever et al., 1991).

The present work was undertaken as part of a study aimed at clarifying the complexity and physiological rôles of the multiple membrane-associated NADH dehydrogenases of $R$. capsulatus. To this end, we have been investigating methods to solubilize the membraneassociated NADH dehydrogenase activities in active form, to analyse the enzymes in the crude soluble extract and to purify and characterize each of the enzymes.

\section{Methods}

Bacterial growth and cell fractionation. Rhodobacter capsulatus strain MT1131 (Zannoni et al., 1980) was grown chemoheterotrophically (aerobically in the dark) at $30^{\circ} \mathrm{C}$ with DL-malate as carbon source using the RCV minimal medium described by Weaver et al. (1975). The cells were harvested in late exponential phase by centifugation. Washed bacterial cells were resuspended in a volume of $50 \mathrm{mM}-\mathrm{HEPES} / \mathrm{NaOH}$, pH 7.4, 5 mM- $\mathrm{MgCl}_{2}, 1 \mathrm{~mm}$-PMSF equal to that of the cell pellet. A few flakes of DNAase were added. The cells were then broken in a precooled French pressure cell (Aminco) at $7.7 \times 10^{6} \mathrm{~kg} \mathrm{~m}^{-2}$. Unbroken cells and cell debris were pelleted by centifugation at $40000 \mathrm{~g}, 4^{\circ} \mathrm{C}$ for 
$20 \mathrm{~min}$ and discarded. The cell-free extract was then centrifuged at $200000 \mathrm{~g}, 4{ }^{\circ} \mathrm{C}$ for $2 \mathrm{~h}$. The supernatant was retained as the soluble fraction (cytoplasm plus periplasm). The pelleted membranes were resuspended in $50 \mathrm{~mm}-\mathrm{HEPES} / \mathrm{NaOH}, \mathrm{pH} 7.4$ unless stated otherwise. Detergent solubilizations were carried out by dropwise addition of detergent from a concentrated stock solution followed by incubation for $30 \mathrm{~min}$ at $4{ }^{\circ} \mathrm{C}$. Unsolubilized material was removed by centrifugation at $100000 \mathrm{~g}$ at $4{ }^{\circ} \mathrm{C}$ for $1 \mathrm{~h}$. Washing of the membranes was carried out in analogous fashion. All purification steps were carried out at $4{ }^{\circ} \mathrm{C}$.

Enzyme assays. Dihydrolipoyl dehydrogenase activity was measured as described by Yanagawa (1979). Pyruvate dehydrogenase activity was assayed as in Visser et al. (1982). The assay was initiated by the addition of sodium pyruvate to a concentration of $5 \mathrm{~mm}$. For the determination of 2-oxoglutarate dehydrogenase activity, $1 \mathrm{~mm}$-2-oxoglutatate was substituted for pyruvate in the pyruvate dehydrogenase assay system. Malate dehydrogenase activity was assayed as in Markwell \& Lascelles (1978) using $270 \mu \mathrm{M}-\mathrm{NADH}$, the reaction being started by addition of $200 \mu \mathrm{M}$-oxaloacetate. The production or consumption of NADH in the above assays was measured spectrophotometrically at $340 \mathrm{~nm}$ using an extinction coefficient of $6.22 \mathrm{~mm}^{-1} \mathrm{~cm}^{-1}$. For NADH, dNADH and NADPH dehydrogenase assays, the concentration of the reduced pyridine dinucleotide was $150 \mu \mathrm{M}$ and the electron acceptor was $1 \mathrm{mM}$ $\mathrm{K}_{3} \mathrm{Fe}(\mathrm{CN})_{6}$. The reactions were followed spectrophotometrically using an $\varepsilon_{410}$ of $1.0 \mathrm{~mm}^{-1} \mathrm{~cm}^{-1}$. NADH-DB oxidoreductase activity was measured spectrophotometrically $\left(\varepsilon_{340} 6.8 \mathrm{~mm}^{-1} \mathrm{~cm}^{-1}\right)$ using an assay mix of $150 \mu \mathrm{M}-\mathrm{NADH}$ and $60 \mu \mathrm{M}-\mathrm{DB}$. The assay mix for the determination of transhydrogenase activities contained $10 \mathrm{~mm}-\mathrm{MgSO}_{4}$ and 16.5 mM-APAD ${ }^{+}$(acetyl pyridine adenine dinucleotide). The stock solution of $\mathrm{APAD}^{+}$stock was prepared in phosphate buffer and its concentration was determined from the $\varepsilon_{260}$ of $16.2 \mathrm{mM}^{-1} \mathrm{~cm}^{-1}$. The reaction was initiated with $150 \mu \mathrm{M}$-electron donor (NADPH or NADH) and the reaction was followed at $450-375 \mathrm{~nm}$ in an Aminco DW2000 dual wavelength spectrophotometer. Concentration changes were calculated from an $\Delta \varepsilon_{450-375}$ of $5 \cdot 1 \mathrm{~mm}^{-1} \mathrm{~cm}^{-1}$. All enzyme assays were at $30^{\circ} \mathrm{C}$ and the assay buffer was $50 \mathrm{~mm}$-HEPES/NaOH, pH 7.4. Detergents above their critical micelle concentrations were included in assays where appropriate. When anaerobiosis was required, stoppered cuvettes containing the samples were alternately evacuated and sparged with argon. When membranes capable of carrying out electron transport to oxygen were present in the assay, advantage was taken of the high affinities of the terminal oxidases to reduce oxygen levels further by inclusion of $10 \mathrm{~mm}$-sodium succinate in the assay samples. The reagent solution employed to initiate the reactions was kept in a sealed anaerobic vial. Withdrawal of the reagent from this vial and transfer to the sample cuvette was by gas-tight Hamilton syringe.

Analytical methods. Protein concentration was estimated using the BCA method (Smith et al., 1985) using BSA (Cohn fraction V) as the standard. SDS-PAGE electrophoresis used the discontinuous buffer system of Laemmli (1970). Samples were heated to $95^{\circ} \mathrm{C}$ for $3 \mathrm{~min}$ prior to electrophoresis. IEF was carried out in a $1 \%$ agarose (BDH IEF agarose) gel using 2\% Ampholines pH 3.5-10.0 and, where required, the appropriate detergent above its critical micelle concentration. The anolyte was $0.5 \mathrm{M}-\mathrm{H}_{3} \mathrm{PO}_{4}$, the catholyte $0.5 \mathrm{M}-\mathrm{NaOH}$. Running conditions were $500 \mathrm{~V}, 15 \mathrm{~mA}$ limiting current for $4 \mathrm{~h}$. The gels were stained for NADH dehydrogenase activity using the method of Owen \& Salton (1975) using TNBT as electron acceptor. The pI of focused proteins (at $4{ }^{\circ} \mathrm{C}$ ) was determined from a linear interpolation between coloured marker proteins (BDH wide range kit, pI values $4 \cdot 7-10 \cdot 6,4^{\circ} \mathrm{C}$ ). These assignments were confirmed by measuring the $\mathrm{pH}$ of solutions prepared by soaking $0.5 \mathrm{~cm}$ gel strips cut from blank control lanes in $2 \mathrm{ml} 50 \mathrm{~mm}-\mathrm{KCl}$ overnight at $4{ }^{\circ} \mathrm{C}$. The $\mathrm{N}$-terminal amino acid sequence of $R$. capsulatus dihydrolipoyl dehydrogenase was determined by the method of Pilkington et al. (1991). Protein was separated by SDS-PAGE and semi-dry blotted onto a PVDF filter (Millipore). The filter-bound polypeptide was sequenced directly on an Applied Biosystems 120A gas-phase sequencer employing PTH analysis.

Materials. $\mathrm{C}_{12} \mathrm{E}_{8}$ was obtained from Fluka, Triton X-100 (specially purified for membrane research) was obtained from Boehringer. SSepharose, S300HR Sephacryl, Polybuffer Exchanger 94, Polybuffers 96 and 74 and Ampholines were obtained from Pharmacia LKB and Aquacide I was from Calbiochem Novabiochem. DB was synthesized by the method of Wan et al. (1975).

\section{Results}

\section{Membranes of $R$. capsulatus have multiple NADH dehydrogenase activities}

Extraction of the membrane vesicles from chemoheterotrophically grown $R$. capsulatus MT1131 with a wide variety of detergents released ferricyanide- or dye-linked NADH dehydrogenase activity(ies) whilst diminishing the NADH-ubiquinone oxidoreductase activity of the insoluble residue (Berks, 1991). The soluble extracts did not catalyse appreciable NADH dehydrogenase activity with ubiquinone analogues as electron acceptors and this low activity was insensitive to rotenone, an inhibitor of the proton-translocating NADH-ubiquinone oxidoreductase. The latter result might arise as a consequence of the fragmentation or delipidation of the protontranslocating NADH-ubiquinone oxidoreductase with attendant loss of activity toward ubiquinone analogues.

We developed the method of NADH-TNBT activity staining of IEF gels to analyse the NADH dehydrogenase activities of the membrane extracts. The gel shown in Fig. 1 is typical. Three types of activity staining band could be identified, the presence or absence of these bands being dependent on the extraction conditions. A Low $\mathrm{pI}$ band $(\mathrm{pI}=5.7)$ was usually a doublet. Staining intensity of this band decreased markedly within a day at $4{ }^{\circ} \mathrm{C}$ or after column chromatography. The Low $\mathrm{pI}$ band is probably derived from an integral membrane protein as it was not released from the membranes by salt washes (e.g. Fig. 1, lane C). The Mid pI band ( $\mathrm{pI}=6.9$ ) was also occasionally a doublet. The protein associated with this activity was precipitated by a $40 \%$ saturation ammonium sulphate cut and was associated with a protein of size $620 \mathrm{kDa}$ as determined by gel filtration of $\mathrm{C}_{12} \mathrm{E}_{8^{-}}$or $\mathrm{NaBr}$-solubilized membranes. This band was shown to be a peripheral membrane protein as it was partially released from the membrane vesicles by salt washes (e.g. Fig. 1C). The High pI band ( $\mathrm{pI}=8.5$ ) was of molecular size $60 \mathrm{kDa}$ as determined by gel filtration chromatography of $\mathrm{C}_{12} \mathrm{E}_{8}$ - or $\mathrm{NaBr}$-solubilized membranes and was probably associated with a peripheral membrane protein as it was at least partially released from membrane vesicles by salt washes (e.g. Fig. 1C).

It has been observed by Tushurashvili et al. (1989) that 


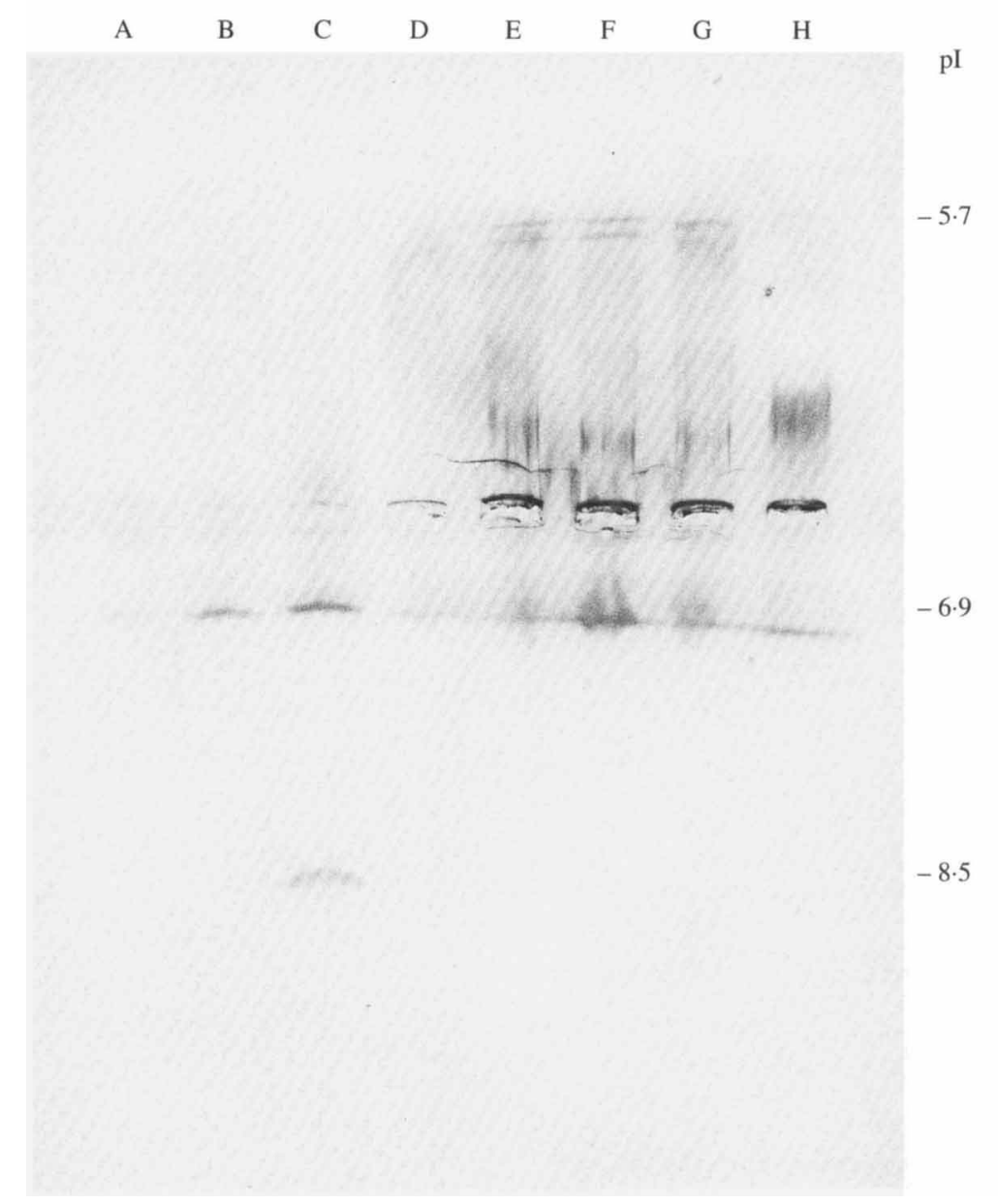

Fig. 1. Effect of different washing conditions on membrane association of dihydrolipoyl dehydrogenase: analysis by isoelectric focusing. The gel contained Ampholines 3.5-10, 0.1\% (w/v) Triton $\mathrm{X}-100$ and was stained for NADH-TNBT activity. Samples were supplemented with $2 \%(\mathrm{w} / \mathrm{v})$ Triton X-100 to allow electrophoretic separation. $R$. capsulatus aerobic membranes at $10 \mathrm{mg}$ protein $\mathrm{ml}^{-1}$ were washed in $50 \mathrm{~mm}$-HEPES/NaOH $\mathrm{pH} 7.4$ supplemented as noted. The washed membrane pellet was resuspended in a volume of $50 \mathrm{~mm}$-HEPES/ $\mathrm{NaOH} \mathrm{pH} 7.4$ equal to the wash volume. Equal quantities $(10 \mu \mathrm{l})$ of all samples were loaded. Lane A, buffer wash supernatant; B, $20 \mathrm{~mm}$-EDTA wash supernatant; C, $0.5 \mathrm{M}-\mathrm{NaCl}$ wash supernatant; D, $2 \%(\mathrm{w} / \mathrm{v})$ Triton $\mathrm{X}-100$ wash supernatant; $E$, buffer wash resuspended pellet; F, 20 mM-EDTA wash resuspended pellet; $\mathrm{G}, 0.5 \mathrm{M}-\mathrm{NaCl}$ wash resuspended pellet; $\mathrm{H}, 2 \%$ $(w / v)$ Triton $X-100$ wash resuspended pellet.
$\mathrm{Mg}^{2+}$ induces a time lag in the NADH-ubiquinone oxidoreductase activity of beef heart submitochondrial particles. This suggested that $\mathrm{Mg}^{2+}$ might bind to the proton-translocating NADH-ubiquinone oxidoreductase of $R$. capsulatus. When $20 \mathrm{~mm}-\mathrm{MgSO}_{4}$ was added to $R$. capsulatus membranes before solubilization, the High pI NADH-TNBT activity staining band became very prominent. Further, the High pI band appeared under detergent solubilization conditions where it had previously been absent. This enhancement of the High $\mathrm{pI}$ band was specific to $\mathrm{Mg}^{2+}$; other mono- or divalent cations at the same concentration did not have the same effect. The effect was only apparent if the $\mathrm{Mg}^{2+}$ was added prior to solubilization. This suggests that the effect of $\mathrm{Mg}^{2+}$ was to release the High $\mathrm{pI}$ band enzyme from the membrane rather than to activate the enzyme.

Material that stained for activity but did not focus was also generally observed in our electrophoretic system (e.g. as in Fig. 1). Large enzymes show a propensity toward isoelectric precipitation during isoelectric focusing. Thus one interpretation of this seemingly unfocused material is that it was intact proton-translocating $\mathrm{NADH}$-ubiquinone oxidoreductase that had not focused properly because of its size. Alternatively, as it was noted that high concentrations of protein stained weakly with the NADH-TNBT activity stain and that the staining of this unfocused material tended to occur after the other bands were fully developed, it is possible that this material stained non-specifically.

From a comparison of rates of rotenone-sensitive reduced nicotinamide nucleotide-DB oxidoreductase activity in membrane vesicles, we established that the $R$. capsulatus proton-translocating NADH-ubiquinone oxidoreductase could utilize deamino-NADH (dNADH) as a substrate as readily as it could NADH (Berks, 1991). Further, the membrane-bound enzyme could oxidize NADPH only at very low rates. It was expected that the electron donor specificity of the membrane-bound proton-translocating NADH-ubiquinone oxidoreductase might be retained by the solubilized enzyme. IEF gels of soluble extracts were therefore stained for dNADH-TNBT, NADPH-TNBT as well as for NADHTNBT activities. Only the Low pI band was stained when NADPH was supplied as the electron donor and this staining was very weak. With dNADH, both the Low and Mid pI bands were stained, though the staining 

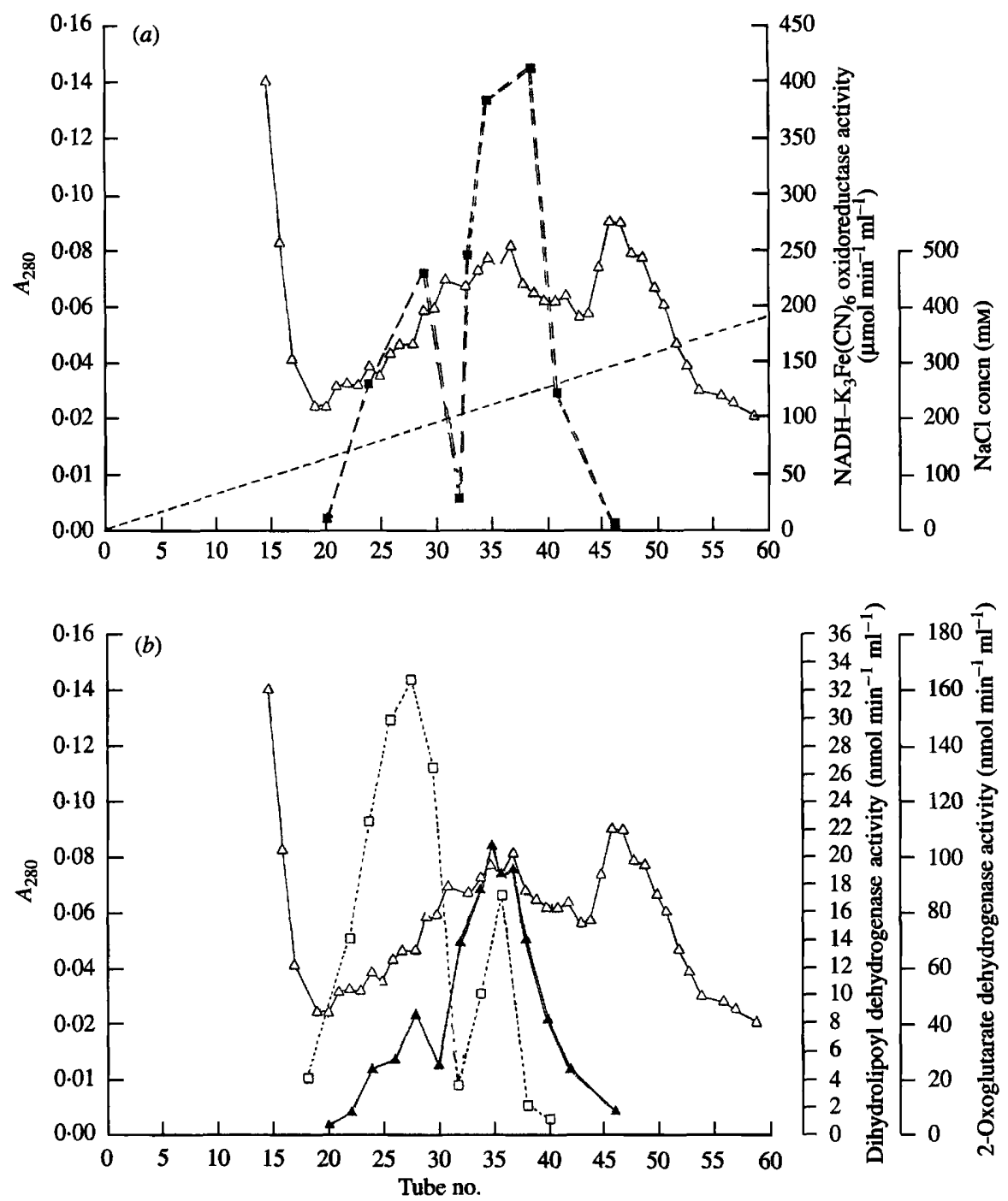

Fig. 2. S-Sepharose column chromatography of $\mathrm{C}_{12} \mathrm{E}_{8} / \mathrm{MgSO}_{4}$ extracted $R$. capsulatus aerobic membranes. Membrane protein (250 mg) was solubilized at $10 \mathrm{mg}$ protein $\mathrm{ml}^{-1}, 2.5 \mathrm{mg} \mathrm{C}_{12} \mathrm{E}_{8} \mathrm{ml}^{-1}$ in $10 \mathrm{mM}-\mathrm{MES} / \mathrm{NaOH} \mathrm{pH} 6.3\left(24^{\circ} \mathrm{C}\right), 20 \mathrm{mM}-\mathrm{MgSO}_{4}$ and loaded on an SSepharose column $\left(17 \times 1.6 \mathrm{~cm}\right.$ diameter). The column was washed with $40 \mathrm{ml} 10 \mathrm{mM}-\mathrm{MES} / \mathrm{NaOH} \mathrm{pH} 6.3\left(24^{\circ} \mathrm{C}\right), 0.25 \mathrm{mg} \mathrm{C}_{12} \mathrm{E}_{8} \mathrm{ml}^{-1}$ then developed with a linear $0-0.5 \mathrm{M}-\mathrm{NaCl}$ gradient (--) in the same buffer. The flow rate was $11 \mathrm{ml} \mathrm{h}^{-1}$ and $2 \mathrm{ml}$ fractions were collected. (a) $\square, \mathrm{NADH}-\mathrm{K}_{3} \mathrm{Fe}(\mathrm{CN})_{6}$ oxidoreductase. (b) $\Delta$, dihydrolipoyl dehydrogenase; $\square$, 2-oxoglutarate dehydrogenase. $\Delta, A_{280}$ in $(a)$ and $(b)$.

intensity of the Mid pI band was relatively somewhat lower than that obtained using NADH as the electron donor (data not shown).

George \& Ferguson (1987) reported that an NADH dehydrogenase that resembles the Flavoprotein fragment of mitochondrial NADH-ubiquinone oxidoreductase was released from the cytoplasmic membrane of Paracoccus denitrificans (a close relative of $R$. capsulatus; Woese, $1987)$ by detergent treatments. In our gel system, Triton$\mathrm{X}-100$-solubilized cytoplasmic membranes of $P$. denitrificans (grown aerobically on glucose or anaerobically with succinate as electron donor and nitrate as electron acceptor) gave only a single activity staining band (data not shown). The staining of this band ( $\mathrm{pI}=5.5$ ) was very much more intense at the same total membrane protein concentration than that of any of the $R$. capsulatus activity staining bands. Thus the NADH-TNBT activity staining pattern of $R$. capsulatus differs from that of $P$. denitrificans, suggesting that the multiple staining pattern seen in $R$. capsulatus is not an artifact of the method.

Isolation of the Mid PI NADH dehydrogenase from the cell membranes of $R$. capsulatus

Extraction of $R$. capsulatus membrane vesicles with the detergent $\mathrm{C}_{12} \mathrm{E}_{8}$ in the presence of $20 \mathrm{mM}-\mathrm{MgSO}_{4}$ was optimal for the release of all three distinct NADH-TNBT activity staining bands. When such an extract was 


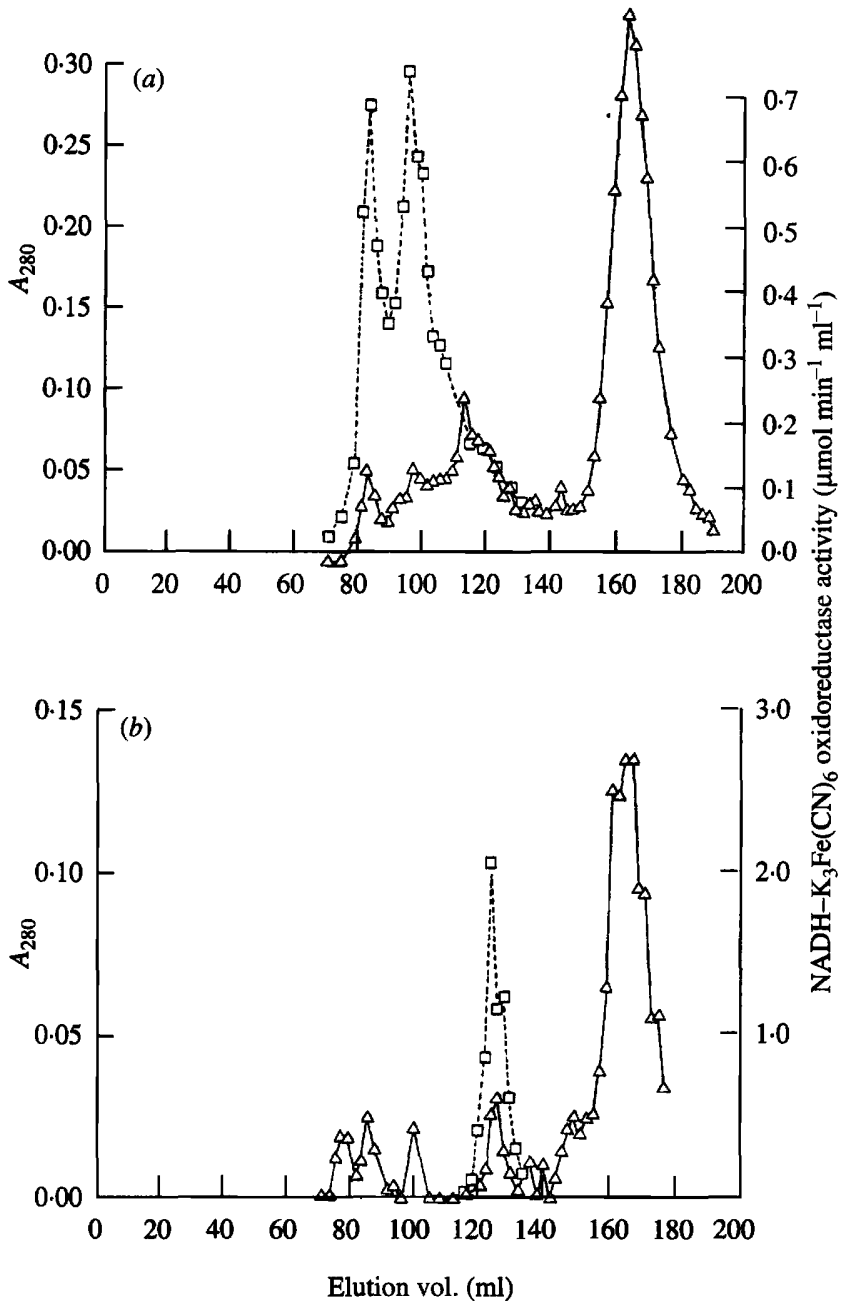

Fig. 3. Sephacryl S300HR gel filtration chromatography of Mid pI band NADH dehydrogenase-containing S-Sepharose column fractions. Samples were concentrated to a volume of $2 \mathrm{ml}$ using Aquacide I and loaded onto a Sephacryl S300HR column ( $1 \mathrm{~m} \times 1.6 \mathrm{~cm}$ diameter $)$. The column buffer was $20 \mathrm{~mm}-\mathrm{HEPES} / \mathrm{NaOH} \mathrm{pH} 7.5\left(24^{\circ} \mathrm{C}\right), 130 \mathrm{~mm}-$ $\mathrm{NaCl}, 0.25 \mathrm{mg} \mathrm{C}_{12} \mathrm{E}_{8} \mathrm{ml}^{-1}$. (a) Pooled NADH-K $\mathrm{K}_{3} \mathrm{Fe}(\mathrm{CN})_{6}$ oxidoreductase activity $(\square)$ containing fractions from the S-Sepharose column (Fig. 2). Flow rate, $20 \mathrm{ml} \mathrm{h}^{-1}$. (b) Pooled NADH-K $\mathrm{K}_{3} \mathrm{Fe}(\mathrm{CN})_{6}$ oxidoreductase activity $(\square)$ containing fractions from the chromatofocusing column. Flow rate, $13 \mathrm{ml} \mathrm{h}^{-1} . \Delta, A_{280}$ in (a) and (b).

Table 1. Enzymic properties of the purified Mid pI band NADH dehydrogenase

\begin{tabular}{lcc}
\hline \hline \multicolumn{1}{c}{ Assay } & $\begin{array}{c}\text { Specific Activity } \\
{\left[\mu \mathrm{mol} \mathrm{min}^{-1}\right.} \\
\left.(\mathrm{mg} \text { protein })^{-1}\right]\end{array}$ & $\begin{array}{c}\text { Percentage of } \\
\text { NADH } \rightarrow \mathbf{K}_{3} \mathrm{Fe}(\mathrm{CN})_{6} \\
\text { oxidoreductase activity }\end{array}$ \\
\hline $\mathrm{NADH} \rightarrow \mathrm{K}_{3} \mathrm{Fe}(\mathrm{CN})_{6}$ & 23 & 100 \\
$\mathrm{dNADH} \rightarrow \mathrm{K}_{3} \mathrm{Fe}(\mathrm{CN})_{6}$ & $3 \cdot 2$ & 14 \\
$\mathrm{NADPH} \rightarrow \mathrm{K}_{3} \mathrm{Fe}(\mathrm{CN})_{6}$ & 0.048 & 0.2 \\
$\mathrm{NADH} \rightarrow \mathrm{DB}$ & 0.13 & 0.6 \\
$\mathrm{NADH} \rightarrow$ lipoic acid & $1 \cdot 4$ & 6 \\
$\mathrm{NADPH} \rightarrow \mathrm{APAD}^{+}$ & 0 & 0 \\
$\mathrm{NADH} \rightarrow \mathrm{APAD}^{+}$ & 0.89 & 4 \\
\hline \hline
\end{tabular}

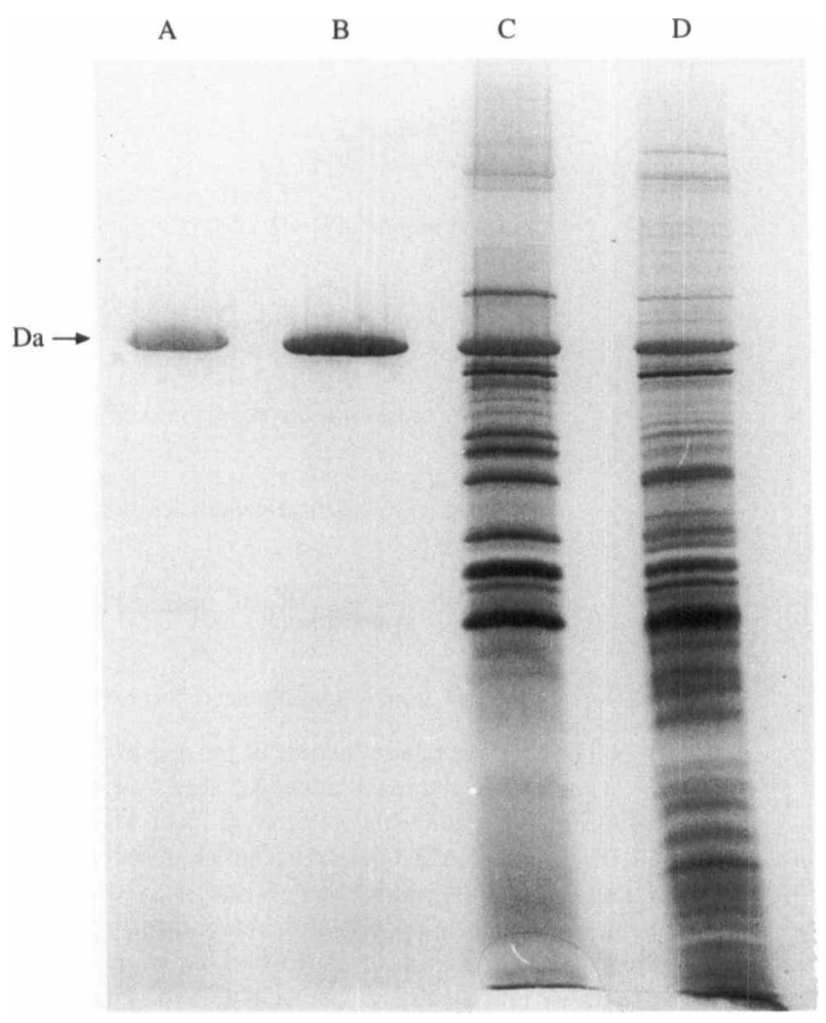

Fig. 4. SDS-PAGE analysis of the purification of the mid pI NADH dehydrogenase. The gel was $12 \%$ polyacrylamide $/ 0 \cdot 3 \%$ bisacrylamide and proteins were detected by silver staining. Lane A, chromatofocusing $\mathrm{NADH}-\mathrm{K}_{3} \mathrm{Fe}(\mathrm{CN})_{6}$ oxidoreductase activity peak reduced with $50 \mathrm{~mm}$-DTT $(11 \mu \mathrm{g}$ protein). B, Chromatofocusing NADH$\mathrm{K}_{3} \mathrm{Fe}(\mathrm{CN})_{6}$ oxidoreductase activity peak reduced with $2 \% \quad \beta$ mercaptoethanol (11 $\mu$ g protein). C, S300HR column pooled NADH$\mathrm{K}_{3} \mathrm{Fe}(\mathrm{CN})_{6}$ oxidoreductase activity peaks (Fig. $3 a$ ) reduced with $2 \%$ $\beta$-mercaptoethanol (17 $\mu \mathrm{g}$ protein). D, S-Sepharose column pooled $\mathrm{NADH}-\mathrm{K}_{3} \mathrm{Fe}(\mathrm{CN})_{6}$ oxidoreductase activity peaks (Fig. 2) reduced with $2 \% \beta$-mercaptoethanol ( $21 \mu \mathrm{g}$ protein).

subjected to cation exchange chromatography, not only the majority of the $\mathrm{NADH}-\mathrm{K}_{3} \mathrm{Fe}(\mathrm{CN})_{6}$ oxidoreductase activity but also the major part of the extracted protein failed to bind to the column. Elution of the bound protein with a gradient of $0-0.5 \mathrm{M}-\mathrm{NaCl}$ released two peaks of $\mathrm{NADH}-\mathrm{K}_{3} \mathrm{Fe}(\mathrm{CN})_{6}$ oxidoreductase activity (Fig. 2). When protein from these peaks was subjected to isoelectric focusing the only NADH-TNBT activity staining band found was the Mid pI band $(\mathrm{pI}=7 \cdot 0)$. If $\mathrm{MgSO}_{4}$ was left out of the extraction buffer, no $\mathrm{NADH}-\mathrm{K}_{3} \mathrm{Fe}(\mathrm{CN})_{6}$ oxidoreductase activity peak was observed. $\mathrm{MgSO}_{4}$ was, therefore, always added during the extraction.

The peaks from the cation exchange column containing $\mathrm{NADH}-\mathrm{K}_{3} \mathrm{Fe}(\mathrm{CN})_{6}$ oxidoreductase activity were pooled (as they both contained the Mid pI band), concentrated and subjected to gel filtration chromatography on Sephacryl S300HR (Fig. 3a). Two peaks of $\mathrm{NADH}-\mathrm{K}_{3} \mathrm{Fe}(\mathrm{CN})_{6}$ oxidoreductase activity were 
R. capsulatus Mid pI NADH dehydrogenase (1-20)

P. putida LPD-Val (5-24)

P. putida LPD-Glc (2-21)

P. putida LPD-3 (2-22)

R. capsulatus carotenoid desaturase I (8-27)

R. capsulatus carotenoid desaturase D (6-25)

P. aeuruginosa $\operatorname{Tn} 501$ mercuric reductase (97-116)

H. sapiens glutathione reductase (19-38)

\section{AEFDVIIIXGGPXAYVXAIR}

. . : : : : : : . : : .:: :

IQTTLLIIGGGPGGYVAAIR

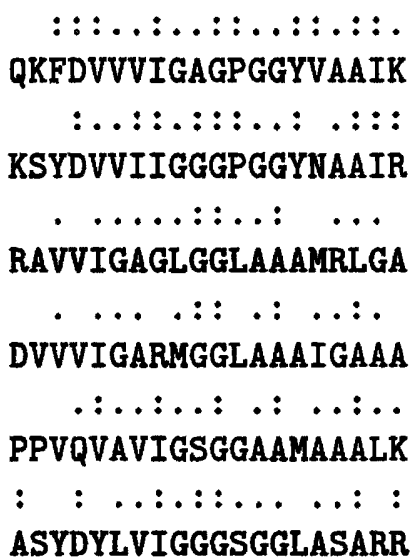

Fig. 5. N-Terminal protein sequences of the mid pI NADH dehydrogenase and comparisons with a representative selection of possible sequence similarities. Standard one-letter amino acid codes are used. Numbering is from the $\mathrm{N}$-terminus of the mature proteins or the $\mathrm{N}$-terminus of the predicted gene product. : is a match, . is a conservative substitution or ambiguous sequence position, both relative to the $R$. capsulatus NADH dehydrogenase sequence. A number of other dihydrolipoyl dehydrogenase sequences have been determined. These sequences show approximately the same degree of similarity to the $R$. capsulatus NADH dehydrogenase sequence as the alignments of dihydrolipoyl dehydrogenases displayed. References for the sequences are: Pseudomonas putida lpdV (LPD-Val) (E from $_{3}$ the branched chain 2-oxoacid dehydrogenase complex), Burns et al. (1989); Pseudomonas putida lpdG (LPD-Glc) (E $\mathrm{E}_{3}$ of the pyruvate dehydrogenase and 2-oxoglutarate dehydrogenase complexes and the L-factor of the glycine oxidation system), Palmer et al. (1991a); Pseudomonas putida LPD-3, Palmer et al. (1991b); Rhodobacter capsulatus carotenoid desaturases $I$ and $D$, Bartley et al. (1990); Pseudomonas aeuruginosa transposon Tn501 mercuric reductase, Brown et al. (1983); Homo sapiens erythrocyte glutathione reductase, Krauth-Siegel et al. (1982).

detected. One eluted at the void volume. The other eluted at a position that corresponded to a size of $620 \mathrm{kDa}$ when the column was calibrated with water-soluble protein standards. Both peaks contained the mid pI NADH-TNBT activity band and both had identical, but complex, SDS-PAGE polypeptide profiles (not shown).

The two activity peaks from the gel filtration column were combined and subjected to chromatofocusing in a pH 8-5 gradient. A single peak of $\mathrm{NADH}-\mathrm{K}_{3} \mathrm{Fe}(\mathrm{CN})_{6}$ oxidoreductase activity was detected eluting at a $\mathrm{pH}$ of 6.1 (not shown). This peak contained the Mid pI NADH-TNBT activity staining band and this corresponded to the only protein in a Coomassie-Blue-stained IEF gel (not shown). A silver-stained SDS-PAGE gel showed only one polypeptide with an estimated molecular mass of $53 \mathrm{kDa}$ (Fig. 4). No further bands were visible if the gel was stained with Coomassie Blue rather than silver.

If the order of the final two steps of the purification procedure, gel filtration and chromatofocusing, was reversed the same $53 \mathrm{kDa} \mathrm{NADH}$ dehydrogenase was purified. However, only a single peak of NADH$\mathrm{K}_{3} \mathrm{Fe}(\mathrm{CN})_{6}$ oxidoreductase activity was found after the gel filtration step (Fig. $3 b$ ). The elution position of this peak was shifted relative to the original purification, the new elution position corresponding to a molecular size of
$80 \mathrm{kDa}$ when the column was calibrated with watersoluble standards. This result suggested that the NADH dehydrogenase was part of a larger complex that is fragmented or disaggregated by chromatofocusing, resulting in the release of the NADH dehydrogenase activity as a $53 \mathrm{kDa}$ monomer.

The yield of purified NADH dehydrogenase from $250 \mathrm{mg}$ membrane protein was $75 \mu \mathrm{g}(0.03 \%)$ and the purification factor 125 .

\section{Properties of the purified Mid pI band NADH dehydrogenase}

Table 1 summarizes the enzymic reactions of the purified NADH dehydrogenase. This NADH dehydrogenase was specific for $\mathrm{NADH}$ when assayed with $\mathrm{K}_{3} \mathrm{Fe}(\mathrm{CN})_{6}$ as electron acceptor. dNADH was a relatively poor electron donor, while the reaction with NADPH was only fractionally greater than the non-enzymic oxidation of NADPH by $\mathrm{K}_{3} \mathrm{Fe}(\mathrm{CN})_{6}$, all in agreement with the qualitative results from activity staining (above).

The purified enzyme did not carry out NADPH $\rightarrow$ $\mathrm{APAD}^{+}$transhydrogenation, a reaction characteristic of $R$. capsulatus $\mathrm{H}^{+}$-nicotinamide nucleotide transhydrogenase (Lever et al., 1991). In contrast, the enzyme did carry out $\mathrm{NADH} \rightarrow \mathrm{APAD}^{+}$transhydrogenation. 
The first 20 amino acids of the $\mathrm{N}$-terminal sequence of the purified NADH dehydrogenase were determined with three ambiguities (Fig. 5). This sequence was compared with the proteins of the Swissprotein database using the GCG7 implementation of program FAST A (Pearson \& Lipman 1988; Devereux et al., 1984). The $R$. capsulatus NADH dehydrogenase sequence showed a high degree of similarity to the flavoprotein disulphide oxidoreductases (Fig. 5), particularly dihydrolipoyl dehydrogenase (dihydrolipoamide: $\mathrm{NAD}^{+}$oxidoreductase; EC 1.6.4.3).

The identity of the purified $R$. capsulatus NADH dehydrogenase with a dihydrolipoyl dehydrogenase was confirmed by assaying for lipoic acid dehydrogenase activity (Table 1). This activity was inhibited by micromolar amounts of arsenite, a reagent specific for vicinal thiols.

\section{Association of dihydrolipoyl dehydrogenase with the cytoplasmic membrane of $R$. capsulatus}

The finding that dihydrolipoyl dehydrogenase could be purified from the membrane fraction of $R$. capsulatus was surprising, since this enzyme is usually a component of the 2-oxoacid dehydrogenase multi-enzyme complexes which are regarded as being water soluble. We therefore investigated the conditions under which dihydrolipoyl dehydrogenase activity was removed from membranes. Membranes were washed with the extraction buffer, 50 mM-HEPES/ $\mathrm{NaOH}, \mathrm{pH} 7 \cdot 4$, supplemented variously with $20 \mathrm{~mm}$-EDTA, $0.5 \mathrm{M}-\mathrm{NaCl}$ or a representative detergent, Triton X-100. Dihydrolipoyl dehydrogenase activity was removed from the membranes most efficiently by $0.5 \mathrm{M}-\mathrm{NaCl}(27 \%)$. Next most effective was 20 mM-EDTA or Triton X-100 (10\% and $11 \%$ respectively). Washing with the extraction buffer alone released the least $(5 \%)$ dihydrolipoyl dehydrogenase activity. In all cases, the majority of dihydrolipoyl dehydrogenase activity remained with the extracted membranes. Electrophoretic analysis of the washes, identifying dihydrolipoyl dehydrogenase activity with intensity of the NADH-TNBT activity of the Mid pI band (Fig. 1) was in broad agreement with the enzyme activity results.

Dihydrolipoyl dehydrogenase was probably derived from a 2-oxoacid dehydrogenase complex. If this was the case, then 2-oxoacid dehydrogenase complexes should have been found in the membrane fraction. Table 2 shows that this was indeed the case. The majority of pyruvate dehydrogenase activity was found to be associated with the membranes. In control experiments malate dehydrogenase, a soluble enzyme of the citric acid cycle, was shown to be virtually absent from the membrane fraction.
Table 2. Distribution of 2-oxoacid dehydrogenase and malate dehydrogenase activities between soluble and membrane fractions of $R$. capsulatus

Washed cells from a 2.5 litre $R$. capsulatus aerobic culture were

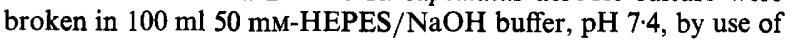
a French pressure cell. The membrane fraction contained $53 \mathrm{mg}$ protein, the soluble fraction (cytoplasm + periplasm) $830 \mathrm{mg}$ protein. Activities of membrane-containing fractions were measured anaerobically. The combined soluble fractions possessed an $\mathrm{NADH}$ oxidase activity of $4 \pm 2 \mathrm{nmol} \mathrm{min}^{-1}(\mathrm{mg} \text { protein })^{-1}$. This activity was not inhibited by anaerobiosis or the NADHubiquinone oxidoreductase inhibitor rotenone. The soluble fraction enzyme activities are corrected for this activity. Quoted values are the means $(n=3)$ for experiments on a single day. Repetition of the experiment gave comparable results.

\begin{tabular}{|c|c|c|c|}
\hline & $\begin{array}{c}\text { Malate } \\
\text { dehydrogenase }\end{array}$ & $\begin{array}{l}\text { 2-Oxoglutarate } \\
\text { dehydrogenase }\end{array}$ & $\begin{array}{c}\text { Pyruvate } \\
\text { dehydrogenase }\end{array}$ \\
\hline $\begin{array}{l}\text { Activity in } \\
\text { membranes } \\
{\left[\text { nmol min }^{-1}\right]} \\
\left.(\text { mg protein })^{-1}\right]\end{array}$ & $400 \pm 100$ & $25 \cdot 3 \pm 0 \cdot 7$ & $600 \pm 300$ \\
\hline $\begin{array}{l}\text { Activity in } \\
\text { soluble fraction } \\
{[\text { nmol min }} \\
\left.(\mathrm{mg} \text { protein })^{-1}\right]\end{array}$ & $1100 \pm 200$ & $6 \pm 3$ & $7 \cdot 2 \pm 0 \cdot 6$ \\
\hline $\begin{array}{l}\text { Total activity } \\
\text { in membranes } \\
\left(\mu \mathrm{mol} \mathrm{min}^{-1}\right)\end{array}$ & 21 & $1 \cdot 3$ & 31.5 \\
\hline 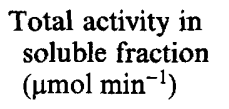 & 913 & 5 & 6 \\
\hline $\begin{array}{l}\text { Activity in } \\
\text { membranes (\%) }\end{array}$ & $2 \cdot 2$ & 21 & 81 \\
\hline
\end{tabular}

\section{Discussion}

An NADH dehydrogenase activity has been purified to homogeneity from membranes of aerobically grown $R$. capsulatus and experimental evidence presented is consistent with this purified enzyme being a dihydrolipoyl dehydrogenase. The enzyme reduced lipoic acid in an arsenite-sensitive reaction and exhibited catalytic activities similar to those of authentic dihydrolipoyl dehydrogenase (Table 1; Yanagawa, 1979). Dihydrolipoyl dehydrogenase subunits have molecular masses, determined by SDS-PAGE, in the range $51-59 \mathrm{kDa}$. The purified $R$. capsulatus NADH dehydrogenase molecular mass determined by this method was $53 \mathrm{kDa}$. Dihydrolipoyl dehydrogenase is a functional dimer. The purified NADH dehydrogenase was sized at $80 \mathrm{kDa}$ by gel filtration, which does not allow assignment as either a monomer or dimer. It was, however, noted that if samples for SDS-PAGE were not boiled a second band at $125 \mathrm{kDa}$ (presumably a dimer) could be seen. Finally, the high amino acid sequence similarity between the purified NADH dehydrogenase and the N-terminus 
of dihydrolipoyl dehydrogenase is evident (Fig. 5). The $R$. capsulatus NADH dehydrogenase sequence shows greater similarity to dihydrolipoyl dehydrogenase sequences than it does to those of glutathione reductase or mercuric reductase. Further, both glutathione reductase and mercuric reductase have $\mathrm{N}$-terminal extensions relative to the dihydrolipoyl dehydrogenases. The sequence of the purified enzyme is not that of one of the carotenoid desaturases of $R$. capsulatus strain B10 (the parent strain of MT1131) (Bartley et al., 1990). It can thus be asserted with confidence that the purified NADH dehydrogenase of $R$. capsulatus is a dihydrolipoyl dehydrogenase. On the basis of the catalytic properties, it is certain that the dihydrolipoyl dehydrogenase purified in this work is not one of the NADH/NADPH dehydrogenases purified from a soluble fraction of $R$. capsulatus strain B10 by Laurinavichene et al. (1987). It is distinct from the membrane NADH dehydrogenase activity purified by Ohshima \& Drews (1981). It may, however, account for the $\mathrm{H}^{+}$-nicotinamide nucleotide transhydrogenase-independent $\mathrm{NADH} \rightarrow \mathrm{APAD}^{+}$activity of $R$. capsulatus membrane vesicles (Lever et al., 1991).

Dihydrolipoyl dehydrogenase (Carothers et al., 1989; Pai, 1991; Williams, 1992) is normally a component of soluble 2-oxoacid dehydrogenase complexes or the soluble glycine cleavage system (Roche \& Patel, 1989; Patel \& Roche, 1990; Perham, 1991; Mattevi et al., 1992) and so purification of this enzyme from a membrane fraction was unexpected. The result was of particular interest because there are a number of observations in the literature of membrane-associated dihydrolipoyl dehydrogenases in prokaryotes (for a review of reports of dihydrolipoyl dehydrogenases with novel functions and of the enzyme bound to the plasma membrane of eukaryotes see Danson, 1988). Dihydrolipoyl dehydrogenase has been found by Owen et al. (1980) in crossed immunoelectrophoresis (CIE) experiments to be associated with the membranes of $E$. coli grown aerobically on succinate/citrate. It was not detected by George \& Ferguson (1987) in analogous CIE experiments in Paracoccus denitrificans, a close relative of $R$. capsulatus (Woese, 1987). This might be because no antibodies to the $P$. denitrificans dihydrolipoyl dehydrogenase were produced. However, no $R$. capsulatus dihydrolipoyldehydrogenase-like band is visible in IEF gels of $P$. denitrificans membranes from cells grown aerobically on glucose or anaerobically on succinate/nitrate (this work). In the thermophile Thermoplasma acidophilum, 30-50\% of the total cellular dihydrolipoyl dehydrogenase activity was found to be associated with the membranecontaining fractions (Smith et al., 1987). In the mycoplasma Acholeplasma laidlawii, a portion of the total pyruvate dehydrogenase activity is recovered in mem- brane fractions (Constantopoulos \& McGarrity, 1987; Wallbrandt et al., 1992). The purinolytic anaerobe Clostridium cylindrosporum possesses a glycine cleavage system, the dihydrolipoyl dehydrogenase component of which shows strong $\mathrm{N}$-terminal homology to other dihydrolipoyl dehydrogenases (Dietrichs et al., 1990). As determined by immunogold electron microscopy, $65 \%$ of the dihydrolipoyl dehydrogenase involved in the glycine cleavage system was associated with the cytoplasmic membrane. In contrast, after the cells had been broken in a French pressure cell, $95 \%$ of the enzyme was found in the soluble fraction (Dietrichs et al., 1991). Finally, in Staphylococcus aureus dihydrolipoyl dehydrogenase was suggested to be bound to membraneassociated ribosomes (Adler \& Arvidson, 1984, 1987; Hemilä, 1991). Similar claims have been made for pyruvate dehydrogenase component $\mathrm{E}_{2}$ (dihydrolipoamide acyltransferase) in Bacillus subtilis (Hemilä et al., 1990) and in Neurospora crassa mitochondria (Kreader et al., 1989; Russell \& Guest, 1991).

It seems probable that the purified dihydrolipoyl dehydrogenase is part of a 2-oxoacid dehydrogenase complex associated with the membrane. There is reasonable evidence, for example, that mitochondrial protontranslocating NADH-ubiquinone oxidoreductase can bind pyruvate and 2-oxoglutarate dehydrogenases (Sumegi \& Srere, 1984; Porpaczy et al., 1987; Fukushima et al., 1989). We have shown that under the cell breakage conditions described in Methods, a substantial proportion of the pyruvate and 2-oxoglutarate dehydrogenase molecules in $R$. capsulatus were associated with the cytoplasmic membranes (Table 2). Some of these membrane-bound 2-oxoglutarate dehydrogenase complexes were present in the $\mathrm{C}_{12} \mathrm{E}_{8} / \mathrm{MgSO}_{4}$ extract. Therefore, it is most likely that the purified dihydrolipoyl dehydrogenase was derived from 2-oxoacid dehydrogenase complexes and was not associated with any novel function. Evidence that supports this view came from the chromatofocusing experiments, which caused a change in the apparent size of dihydrolipoyl dehydrogenase as measured by gel filtration from $\geqslant 600 \mathrm{kDa}$ to $80 \mathrm{kDa}$. This suggests that dihydrolipoyl dehydrogenase is dissociating from a larger complex under these chromatographic conditions. Dihydrolipoyl Dehydrogenase is non-covalently bound to the core $\mathrm{E}_{2}$ proteins in 2oxoacid dehydrogenase complexes. If chromatofocusing can release dihydrolipoyl dehydrogenase molecules from these complexes, then it is perhaps not surprising that IEF gives a single band from gel filtration NADH$\mathrm{K}_{3} \mathrm{Fe}(\mathrm{CN})_{6}$ oxidoreductase activity peaks of differing molecular sizes. The strongest NADH-TNBT activity staining band in the soluble extract of aerobic $R$. capsulatus has the same $\mathrm{pI}$ as the purified membraneassociated dihydrolipoyl dehydrogenase (not shown), 
suggesting that the dihydrolipoyl dehydrogenase activity in both fractions is due to the same enzyme. This again argues that the membrane-bound dihydrolipoyl dehydrogenase is derived from a 2-oxoacid dehydrogenase complex and that it is not a component of a novel enzyme.

If the purified dihydrolipoyl dehydrogenase was derived from a 2-oxoacid dehydrogenase complex, it was possible that dihydrolipoyl dehydrogenase and the dehydrogenase activity would co-migrate on the S-Sepharose column used as the first step in the dihydrolipoyl dehydrogenase purification procedure. Fig. 2(a) shows that this is not the case. No pyruvate dehydrogenase activity was bound to the column but two peaks of 2-oxoglutarate dehydrogenase activity were detected. The major 2-oxoglutarate dehydrogenase activity peak co-migrated with a minor dihydrolipoyl dehydrogenase and $\mathrm{NADH}-\mathrm{K}_{3} \mathrm{Fe}(\mathrm{CN})_{6}$ oxidoreductase activity peak. A second, small, 2-oxoglutarate dehydrogenase activity peak co-migrated with the main dihydrolipoyl dehydrogenase and $\mathrm{NADH}-\mathrm{K}_{3} \mathrm{Fe}(\mathrm{CN})_{6}$ oxidoreductase activity peaks. A possible explanation is that some of the 2-oxoglutarate dehydrogenase complexes lose dihydrolipoyl dehydrogenase subunits during chromatography. This has been observed (Williams, 1976). It is suggested that dihydrolipoyl dehydrogenase and $\mathrm{NADH}-\mathrm{K}_{3} \mathrm{Fe}(\mathrm{CN})_{6}$ oxidoreductase activities are inhibited in the intact complex by steric factors and/or regulatory mechanisms forcing the enzyme to operate in the physiological reaction direction. It follows that if dihydrolipoyl dehydrogenase were released from the 2oxoglutarate dehydrogenase complex during chromatography, then these activities would be expected to increase.

The membrane-association of dihydrolipoyl dehydrogenase in $R$. capsulatus is not an artifact caused by part of the cell soluble fraction being trapped inside the membrane vesicles. Dihydrolipoyl dehydrogenase activity is detectable in unsolubilized membrane preparations. Further, addition of $1 \%(\mathrm{w} / \mathrm{v})$ Triton X-100 to $1 \mathrm{mg}$ membrane protein $\mathrm{ml}^{-1}$ in the assay mix (sufficient to cause a loss of sample turbidity and of NADH oxidase activity, indicating total membrane solubilization) did not change the dihydrolipoyl dehydrogenase activity.

A simple explanation of the membrane association of the 2-oxoacid dehydrogenase complexes in $R$. capsulatus could have been that it is an artifact resulting from the use of high speed centrifugation to pellet the cell membrane vesicles. The 2-oxoacid dehydrogenase complexes are large enzymes and might sediment during the high speed centrifugation needed to recover the $R$. capsulatus membrane vesicles $(200000 \mathrm{~g}$ for $2 \mathrm{~h}$ ) or used to pellet unsolubilized membrane components after detergent treatment $(100000 \mathrm{~g}$ for $1 \mathrm{~h})$. This explanation is not consistent with the observation that a greater proportion of $R$. capsulatus pyruvate dehydrogenase complexes than 2-oxoglutarate dehydrogenase complexes are membrane associated (Table 2) when both complexes are likely to be of comparable size. It also does not explain why no obvious dihydrolipoyl dehydrogenase activity band is seen in membranes from $P$. denitrificans centrifuged and solubilized under the same conditions as the $R$. capsulatus membrane samples (B. C. Berks, unpublished observations). Further, a membraneassociated dihydrolipoyl dehydrogenase was detectable in E. coli even though spins of $30000 \mathrm{~g}$ or less for $30 \mathrm{~min}$ were used in the vesicle preparations (Owen et al., 1980).

The procedure for determining NADH dehydrogenase activities using isoelectric focusing should be of general value in identifying proteins with these activities in bacterial membranes. In addition to the Mid $\mathrm{pI}$ band NADH dehydrogenase that we characterized, the work described in this paper enabled us to identify two additional NADH dehydrogenase activities in $R$. capsulatus. The Low $\mathrm{pI}$ band was probably derived from the mitochondrial-type NADH-ubiquinone oxidoreductase as it was derived from an integral membrane protein and exhibited the correct substrate specificities. Further, it had a similar pI, to, and was unstable like, the Flavoprotein fragment of $P$. denitrificans NADHubiquinone oxidoreductase (George \& Ferguson, 1987). The High pI band is possibly associated with the NADH dehydrogenase purified from $R$. capsulatus membranes by Ohshima \& Drews (1981). Further research will be necessary to determine the validity of these suggestions.

We wish to thank Drs J. E. Walker and J. M. Skehel for determining the dihydrolipoyl dehydrogenase $\mathrm{N}$-terminal sequence. We are grateful to Drs Baz Jackson and Tracy Palmer for assistance with the transhydrogenase assays. B.C.B. thanks the Association of Commonwealth Universities for the award of a Commonwealth Scholarship. A.G.M. thanks the Royal Society for a 1983 University Research Fellowship.

\section{References}

Adler, L.-Å. \& ARvidson, S. (1984). Detection of a membraneassociated protein on detached membrane ribosomes in Staphylococcus aureus. Journal of General Microbiology 130, 1673-1682.

ADLER, L.-Å. \& ARVIDSON, S. (1987). Correlation between the rate of exoprotein synthesis and the amount of the multiprotein complex on membrane-bound ribosomes (MBRP-complex) in Staphylococcus aureus. Journal of General Microbiology 133, 803-813.

Bartley, G. E., Schmidhauser, T. J., YANofsky, C. \& Scolnik, P. A. (1990). Carotenoid desaturases from Rhodobacter capsulatus and Neurospora crassa are structurally and functionally conserved and contain domains homologous to flavoprotein disulfide oxidoreductases. Journal of Biological Chemistry 265, 16020-16024.

BERKS, B. C. (1991). Molecular characterisation of bacterial electron transport proteins. D.Phil. thesis, University of Oxford.

Berks, B. C. \& Ferguson, S. J. (1991). Simplicity and complexity in electron transfer between NADH and $c$-type cytochromes in bacteria. Biochemical Society Transactions 19, 581-587. 
Brown, N. L., Ford, S. J., Pridmore, R. D. \& Fritzinger, D. C. (1983). Nucleotide sequence of a gene from the Pseudomonas transposon Tn501 encoding mercuric reductase. Biochemistry 22, 4089-4095.

Burns, G., Brown, T., Hatter, K. \& SoKatch, J. R. (1989). Sequence analysis of the lpd gene for lipoamide dehydrogenase of branchedchain-oxoacid dehydrogenase of Pseudomonas putida. European Journal of Biochemistry 179, 61-69.

Carothers, D. J., Pons, G. \& Patel, M. S. (1989). Dihydrolipoamide dehydrogenase: functional similarities and divergent evolution of the pyridine nucleotide-disulfide oxidoreductases. Archives of Biochemistry and Biophysics 268, 409-425.

Constantopoulos, G. \& McGarrity, G. (1987). Activities of oxidative enzymes in mycoplasmas. Journal of Bacteriology 169, 2012-2016.

Danson, M. J. (1988). Dihydrolipoamide dehydrogenase: a 'new' function for an old enzyme? Biochemical Society Transactions 16, 87-89.

Devereux, J., Haeberli, P. \& Smithies, O. (1984). A comprehensive set of sequence analysis programs for the VAX. Nucleic Acids Research 12, 387-395.

Dietrichs, D., MeYer, M., Schmidt, B. \& ANDreesen, J. R. (1990). Purification of NADPH-dependent electron-transferring flavoproteins and $\mathrm{N}$-terminal protein sequence data of dihydrolipoamide dehydrogenases from anaerobic, glycine-utilizing bacteria. Journal of Bacteriology 172, 2088-2095.

Dietrichs, D., BahNweG, M., MAYer, F. \& ANDReESEN, J. R. (1991). Peripheral localization of the dihydrolipoamide dehydrogenase in the purinolytic anaerobe Clostridium cylindrosporum. Archives of Microbiology 155, 412-414.

DUPUIS, A. (1992). Identification of two genes of Rhodobacter capsulatus coding for proteins homologous to the NDl and $23 \mathrm{kDa}$ subunits of the mitochondrial Complex I. FEBS Letters 301, 215-218.

Fukushima, T., Decker, R. V., Anderson, W. M. \& Spivey, H. O. (1989). Substrate channeling of NADH and binding of dehydrogenases to complex I. Journal of Biological Chemistry 264, 16483-16488.

GeORGE, C. L. \& Ferguson, S. J. (1987). Immunochemical probing of the structure and cofactor of NADH dehydrogenase from Paracoccus denitrificans. Biochemical Journal 244, 661-668.

HemILÄ, H. (1991). Lipoamide dehydrogenase of Staphylococcus aureus: nucleotide sequence and sequence analysis. Biochimica et Biophysica Acta 1129, 119-123.

Hemilä, H., Palva, A., Paulin, L., Arvidson, S. \& Palva, I. (1990). Secretory $\mathbf{S}$ complex of Bacillus subtilis: sequence analysis and identity to pyruvate dehydrogenase. Journal of Bacteriology 172, 5052-5063.

KLEMME, J.-H. (1969). Studies on the mechanism of NADphotoreduction by chromatophores of the faculative phototroph Rhodopseudomonas capsulata. Zeitschrift für Naturforschung 24b, 67-76.

Krauth-Siegel, R. L., Blatterspiel, R., Saleh, M., Schiltz, E., SCHIRMER, R. H. \& UNTUCHT-GRAU, R. (1982). Glutathione reductase from human erythrocytes. The sequences of the NADPH and of the interface domain. European Journal of Biochemistry 121, 259-267.

Kreader, C. A., Langer, C. S. \& Heckman, J. E. (1989). A mitochondrial protein from Neurospora crassa detected both on ribosomes and in membrane fractions. Analysis of the gene, the message, and the protein. Journal of Biological Chemistry 264, 317-327.

LAEMMLI, U. K. (1970). Cleavage of structural proteins during the assembly of the head of bacteriophage T4. Nature, London 227 , 680-685.

LA MoniCA, R. F. \& MARRS, B. L. (1976). The branched respiratory system of photosynthetically grown Rhodopseudomonas capsulata. Biochimica et Biophsica Acta 423, 431-439.

Laurinavichene, T. V., Agakishiev, A. G. \& Gogotov, I. N. (1987). Properties and synthesis regulation of NAD(P)H dehydrogenases from Rhodobacter capsulatus. Biochimica et Biophysica Acta 893, 386-397.
Lever, T. M., Palmer, T., Cunningham, I. J., Cotton, N. P. J. \& JACKSON, J. B. (1991). Purification and properties of the $\mathbf{H}^{+}-$ nicotinamide nucleotide transhydrogenase from Rhodobacter capsulatus. European Journal of Biochemistry 197, 247-255.

Marrs, B., Stahl, C. L., Lien, S. \& Guest, H. (1972). Biochemical physiology of a respiratory deficient mutant of the photosynthetic bacterium Rhodopseudomonas capsulata. Proceedings of the National Academy of Sciences of the United States of America 69, 916-920.

MARKWEll, J. P. \& LASCELles, J. K. (1978). Membrane-bound, pyridine nucleotide-independent L-lactate dehydrogenase of Rhodopseudomonas sphaeroides. Journal of Bacteriology 133, 593-600.

Mattevi, A., DE KoK, A. \& Perham, R. N. (1992). The pyruvate dehydrogenase complex. Current Opinion in Structural Biology 2, 877-887.

Meinhardt, S. W., Matsushita, K., Kaback, H. R. \& Ohnishi, T. (1989). EPR characterization of the iron-sulphur containing NADHubiquinone oxidoreductase of the Escherichia coli aerobic respiratory chain. Biochemistry 28, 2153-2160.

Meinhardt, S. W., Wang, D.-C., Hon-nami, K., Yagi, T., Oshima, T. \& OHNISHI, T. (1990). Studies on the NADH-menaquinone oxidoreductase segment of the respiratory chain in Thermus thermophilus HB-8. Journal of Biological Chemistry 265, 1360-1368.

OHSHIMA, T. \& DREWS, G. (1981). Isolation and partial characterization of the membrane-bound NADH dehydrogenase from the phototrophic bacterium Rhodopseudomonas capsulata. Zeitschrift für Naturforschung 36c, 400-406.

Owen, P., Kaback, H. R. \& Graeme-CoOKe, K. A. (1980). Identification of antigen 19/27 as dihydrolipoyl dehydrogenase and its probable involvement in ubiquinone-mediated NADH-dependent transport phenomena in membrane vesicles of Escherichia coli. FEMS Microbiology Letters 7, 345-348.

OWEN, P. \& Salton, M. R. J. (1975). Antigenic and enzymatic architecture of Micrococcus lysodeikticus membranes established by crossed immunoelectrophoresis. Proceedings of the National Academy of Sciences of the United States of America 72, 3711-3715.

PAI, E. F. (1991). Variations on a theme: the family of FAD-dependent $\mathrm{NAD}(\mathrm{P}) \mathrm{H}$-(disulphide)-oxidoreductases. Current Opinion in Structural Biology 1, 796-803.

Palmer, J. A., Hatter, K. \& Sokatch, J. R. (1991a). Cloning and sequence analysis of the LPD-glc structural gene of Pseudomonas putida. Journal of Bacteriology 173, 3109-3116.

Palmer, J. A., Madhusudhan, K. T., Hatter, K. \& Sokatch, J. R. $(1991 \mathrm{~b})$. Cloning, sequence and transcriptional analysis of the structural gene for LPD-3, the third lipoamide dehydrogenase of Pseudomonas putida. European Journal of Biochemistry 202, 231-240.

Patel, M. S. \& Roche, T. E. (1990). Molecular biology and biochemistry of pyruvate dehydrogenase complexes. FASEB Journal 4, 3224-3233.

Pearson, W. R. \& Lipman, D. J. (1988). Improved tools for biological sequence comparison. Proceedings of the National Academy of Sciences of the United States of America 85, 2444-2448.

Perham, R. N. (1991). Domains, motifs, and linkers in 2-oxo acid dehydrogenase multienzyme complexes: a paradigm in the design of a multifunctional protein. Biochemistry 30, 8501-8512.

Pilkington, S. J., Skehel, J. M., Gennis, R. B. \& Walker, J. E. (1991). Relationship between mitochondrial NADH-ubiquinone reductase and a bacterial NAD-reducing hydrogenase. Biochemistry 30, 2166-2175.

Porpaczy, Z., Sumegi, B. \& AlkoNyi, I. (1987). Interaction between NAD-dependent isocitrate dehydrogenase, $\alpha$-ketoglutarate dehydrogenase complex, and NADH:ubiquine oxidoreductase. Journal of Biological Chemistry 262, 9509-9514.

Roche, T. E. \& PATEL, M. S. (editors) (1989). Alpha-keto acid dehydrogenase complexes: organization, regulation, and biomedical ramifications. Annals of the New York Academy of Sciences 573, $1-462$.

Russell, G. C. \& Guest, J. R. (1991). Sequence similarities within the family of dihydrolipoamide acyltransferases and discovery of a previously unidentified fungal gene. Biochimica et Biophysica Acta 1076, 225-232.

Smith, P. K., Krohn, R. I., Hermanson, G. T., Mallia, A. K., 
Gartner, F. H., Provenzano, M. D., Fujimoto, E. K., Goeke, N. M., OLSON, B. J. \& KLENK, D. C. (1985). Measurement of protein using bicinchoninic acid. Analytical Biochemistry 150, 76-85.

Smith, L. D., Bungard, S. J., Danson, M. J. \& Hough, D. W. (1987). Dihydrolipoamide dehydrogenase from the thermoacidophilic archaebacterium Thermoplasma acidophilum. Biochemical Society Transactions 15, 1097

Sumegi, B. \& SRere, P. A. (1984). Complex I binds several mitochondrial NAD-coupled dehydrogenases. Journal of Biological Chemistry 259, 15040-15045.

Tushurashvili, P. R., Dekanosidze, N. Z., Inasaridze, N. P., Kekelidze, T. N., Tsartsidze, M. A. \& Lomasadze, B. A. (1989). Hysteritic interaction of $\mathrm{NADH}$ and $\mathrm{Mg}^{2+}$ with mammalian NADH: CoQ reductase from beef heart. FEBS Letters 244, 268-270.

Visser, J., Kester, H., Jeyaseelan, K. \& Topp, R. (1982). Pyruvate dehydrogenase complex from Bacillus. Methods in Enzymology 89, 399-407.

Wallbrandt, P., Tegman, V., Jonsson, B.-H. \& Wieslander, A (1992). Identification and analysis of the genes coding for the putative pyruvate dehydrogenase enzyme complex in Acholeplasma laidlawii. Journal of Bacteriology 174, 1388-1396.

Wan, Y.-H., Williams, R. H., Folkers, K., LeUnG, K. H. \& Racker, E. (1975). Low molecular weight analogues of coenzyme $Q$ as hydrogen acceptors and donors in systems of the respiratory chain. Biochemical and Biophysical Research Communications 63, 11-15.

Weaver, P. F., WaLl, J. D. \& GeSt, H. (1975). Characterization of Rhodobacter capsulatus. Archives of Microbiology 105, 207-216.

Williams, C. H. (1976). Flavin-containing dehydrogenases. In The Enzymes, 3rd edn, vol. 13, pp. 207-216. Edited by P. D. Boyer. New York: Academic Press.

Williams, C. H. (1992). Lipoamide dehydrogenase, glutathione reductase, thioredoxin reductase and mercuric reductase-family of flavoenzyme transhydrogenases. In Chemistry and Biochemistry of Flavoenzymes, vol. 3, pp. 121-211. Edited by F. Müller. Boca Raton: CRC Press.

WoEse, C. R. (1987). Bacterial evolution. Microbiological Reviews 51, 221-271.

YAGI, T. (1991). Bacterial NADH-quinone oxidoreductases. Journal of Bioenergetics and Biomembranes 23, 211-225.

YanAGaWA, H. (1979). Asparagusate dehydrogenase and lipoyl dehydrogenase from asparagus. Methods in Enzymology 62, 172-181.

Zannoni, D., Prince, R. C., Dutton, P. L. \& Marrs, B. L. (1980). Isolation and characterization of a cytochrome $c_{2}$-deficient mutant of Rhodopseudomonas capsulata. FEBS Letters 113, 289-293.

ZANNONI, D. \& INGLEDEW, W. J. (1983). Rhodopseudomonas capsulata respiratory dehydrogenase mutants: an electron paramagnetic resonance study. FEMS Microbiology Letters 17, 331-334. 